\title{
Front with Heavy Rainfalls in the Asian Subtropical Humid Region in a 6-Level 79 km-Mesh Primitive Equation Model
}

\author{
By K. Ninomiya and Y. Tatsumi \\ Electronic Computation Center, Japan Meteorological Agency, Tokyo 100, Japan \\ (Manuscript received 4 February 1980, in revised form 15 April 1980)
}

\begin{abstract}
Real data forecast experiments of heavy rainfalls in Baiu front (a front in the Asian subtropical humid region) are made for two typical cases by using a 6-level $77 \mathrm{~km}$-mesh regional primitive equation model.

We show first that the moist convective adjustment scheme which has been used in coarse-mesh models is not always suitable for the present model as the scheme tends to produce heavy rainfalls in the area far south to the frontal zone. In order to confine heavy rainfalls within the frontal zone or in the vicinity of frontal disturbances, we improved the scheme by controling the adjustment through low-level vorticity and by modifying the critical lapse rate used in the scheme.

Detailed analysis is made for two cases of Baiu frontal heavy rainfalls predicted by the model including the improved adjustment scheme. The characteristic features of Baiu front associated with heavy rainfalls (i.e., concentration of heavy rainfalls in a zone to the south of subtropical jet stream, formation of a low-level strong wind zone to the south of the heavy rainfall zone, moist tongue and a zone of convective warming in the middle troposphere) are accurately predicted.
\end{abstract}

\section{Introduction}

The numerical prediction of intense convective rainfalls has been a problem for many years. Since convective rain tends to concentrate within a narrow zone, the increase of grid resolution of the prediction model has been supposed to be necessary for the accurate prediction. Many authors (e.g., Hovermale (1975), Perkey (1976), Miyakoda and Rosati (1977), Anthes and Keyser (1979)) stressed in their recent forecast experimental studies using fine-mesh (or meso-mesh) primitive equation models that improvement in prediction accuracy of rainfall can be achieved through increased grid resolution. It is also stated by Keyser et al. (1978) in a experimental study of front that the fine-mesh primitive equation model output can save as a data source for diagnostic studies of subsynoptic-scale disturbance. It should be noted that the cases studied in the aforementioned works are for heavy rainfalls associated with disturbances of the polar frontal zone in the winter spring season, where the atmosphere is characterized by strong baroclinicity.
During the presummer rain season (June-July), Baiu front (a stational front in the Asian subtropical humid region) lies along the Japan Islands $(30-35 \mathrm{~N})$ and weak frontal disturbances frequently bring strong convective rainfalls. Many observational studies have shown that the features of Baiu front and associated disturbances are significantly different from those in polar frontal regions. It has been infered in these works that Baiu front is enhanced in the vicinity of the Japan Islands through thermodynamic influences of cumulus ensembl.

The numerical prediction of rainfalls in the summer season, especially in the Baiu season, has been a problem in Japan. Nitta et al. (1979) mentioned that the forecast efficiency of precipitation by 6 -level (in $p$-coordinate) $150 \mathrm{~km}$ mesh operational prediction model (6L FLM) of JMA is significantly low in the summer season. It seems to the authors that the behaviour and the structure of Baiu front in the operational prediction models are not fully examined yet.

Ninomiya (1980) has demonstrated, in the control experiment using a coarse-mesh primitive equation model, that Baiu front is enhanced 
along the northern periphery of tropical marine air mass through thermodynamic influences of cumulus ensemble. Of course, neither the concentration of heavy rainfalls in a narrow zone nor precise features of the front is simulated in his work because of the low resolution of the model. It is also a remaining problem to confirm whether the convective adjustment scheme designed and tested on large meshes is adequate or not to forecast subtropical heavy rainfalls in small mesh model.

In the present real data forecast experiment using 6-level $77 \mathrm{~km}$-mesh primitive equation model, we intend to simulate Baiu frontal rainfalls. For this purpose we improve the convective adjustment scheme used in coarse-mesh models. We also examine the features of the predicted front by comparing with the observed features.

\section{Observed features of Baiu front and heavy rainfalls}

Prior to the experiment we will describe the observed characteristics of Baiu front associated with heavy rainfalls. Detailed observational studies by Matsumoto et al. $(1970,1971)$, Matsumoto and Ninomiya (1971), Ninomiya and Akiyama (1971, 1974), Akiyama (1973a, b, 1975, 1978, 1979), Yoshizumi (1977a, b), Ninomiya (1978), Ninomiya and Yamazaki (1979) have revealed the characteristic features of Baiu front.

Those features are;

(1) Baiu front is formed along the northern boundary of tropical marine air mass. The tempcrature gradient is usually weak in the frontal zone, while the moisture gradient is strong.

(2) Convective rainfalls of $\sim 100 \mathrm{~mm} /$ day concentrated within narrow $(\sim 100 \mathrm{~km})$ arca occure frequently in the frontal zone.

(3) In $850 \sim 700 \mathrm{mb}$, the moist zone (moist tongue) is formed along the heavy rainfall zone.

(4) In $500 \sim 300 \mathrm{mb}$ layer, the warm belt is formed over the rainfall zone. Heat energy budget analysis indicates that the warming is attributed to "convective heating".

(5) Release of thermal instability is limited within the heavy rainfall zone.

(6) Frontal layer is characterized by neutral

* Heating due to release of latent heat and vertical convergence of convective heat transport is noted as "convective heating" in the present paper for convenience's sake. stratification which is resulted from the release of instability, while the tropical air mass to the south of the front is characterized by strong convective (potential) instability.

(7) Zone of low level ( $700 \mathrm{mb})$ strong wind (somctimes called as a low-level jet stream) appears along the heavy rainfall zone. Winds in the zone indicate strong ageostrophic component. The momentum budget calculations suggest that the generation of ageostrophic wind is mainly attributed to convective transport of momentum.

(8) The heavy rainfall zone is usually located to the south of the subtropical jet's axis and to the north of the low level strong wind zone.

(9) Wcak large-scale $(\sim 3,000 \mathrm{~km}$ in wave length) and medium-scale $(\sim 1,000 \mathrm{~km}$ in wave length) frontal disturbances sometimes bring the heavy convective rainfalls. The vertical axis of these disturbances tend to incline towards north with height. (See Tokioka (1974) for the theoretical considerations.)

It is an important object of this experiment to explore for what extent the present $77 \mathrm{~km}$ mesh model can simulate the aforcmentioned characteristics of Baiu front. It should be noted that the strong ageostrophic winds in lower layers described in (7) will not be produced in the present experiment because the process of convective momentum transport is not formulated in the present model.

\section{Description of model and experiment}

\section{Description of model}

Recently Tatsumi designed 6-level ( $\sigma$-coordinate) $127 \mathrm{~km}$-mesh (at $60 \mathrm{~N}$ ) primitive equation model and has examined 24-hour forecast performance for $\sim 30$ cases of various situations. The basic structure (i.e., grid structure, govering equations and their finite difference forms and explicit time integration scheme) of the Tatsumiexplicit model is identical with those of 4 Level Northern Hemispherical Model-2 (4L NHM-2), which was designed by Kikuchi et al. (1977) and was used as an opcrational prediction model of JMA in 1978 79, except the mesh size, vertical resolution and lateral boundary condition.

For the present experiment, we reduce the mesh size of Tatsumi-explicit model $(\sim 127 \mathrm{~km}$ at $60 \mathrm{~N})$ to $\sim 77 \mathrm{~km}$ at $30 \mathrm{~N}(\sim 95 \mathrm{~km}$ at $60 \mathrm{~N})$ and improve the moist convective adjustment scheme.

Since the description of $4 \mathrm{~L}$ NHM-2 was made by Kikuchi et al. (1977) and the explanation of 


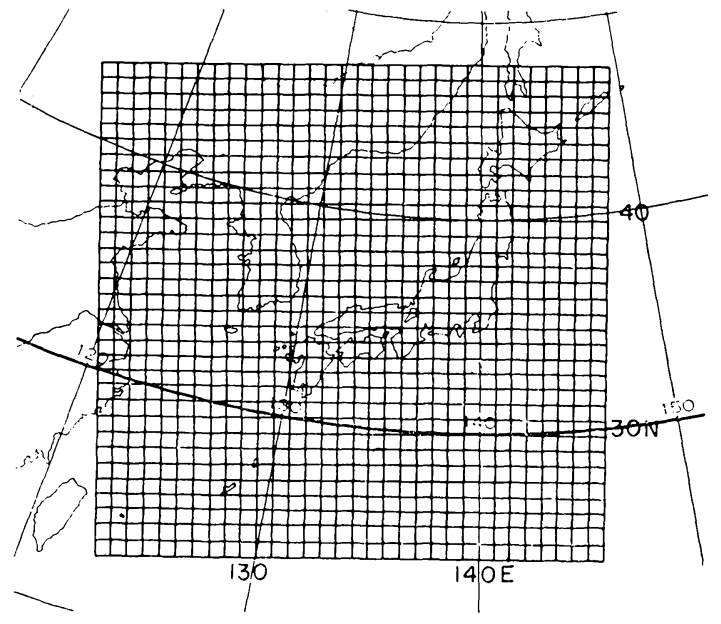

Fig. $1 \mathrm{~A}$ Domain and grid system of the present model.

Tatsumi-explicit model will be given elsewhere, we give only the following brief description of the model used in the present experiment;

Grid distance: $77 \mathrm{~km}$ at $30 \mathrm{~N}(95 \mathrm{~km}$ at $60 \mathrm{~N})$

Domain: Square area of $33 \times 33$ grid in polar stereographic projection (see Fig. 1A).

Vertical coordinate: 6 levels (uniform interval) in $\sigma$-system with the top at $100 \mathrm{mb}$.

Lateral boundary condition: This model is nested in one way in 4L NHM-2 through Davies boundary condition (Davies 1976). We perform the 24-hour forecast by $4 \mathrm{~L}$ NHM-2 first and the forecasted values are used as boundary values for the present model through Davies boundary condition. Vertical resolution is not the same in both models and vertical interpolation is used.

Physical process:

1) Sensible and latent heat exchange between the sea and the air.

2) Surface flux of momentum over the sea and land.

3) Condensation and released latent heat caused by grid-scale vertical motions.

4) Thermodynamic process of subgrid-scale convective motions is formulated in the convective adjustment scheme.

5) Subgrid-scale horizontal diffusions of momentum, temperature and water vapor in Fickiantype formulation (e.g., $\nu \nabla^{2} T$ ). The numerical value of coefficient $\nu$ is determined based on the two dimensional turbulence theory (Leith 1969) as $\nu=\gamma|\nabla \zeta| d^{3}$ ( $\zeta$ relative vorticity, $d$ grid distance) and an non-dimensional constant $\gamma$ is set
1.00 at the present study (c.f., 0.25 in $151 \mathrm{~km}$ mesh 6L FLM of JMA (Nitta et al. 1979)).

6) Vertical diffusions of momentum, temperature and water vapor in the lowest two layers.

7) Orographic effects with a smoothed topography. The topography used in $4 \mathrm{~L}$ NHM-2 is interpolated for the present model.

8) Uniform cooling to counterbalance the total diabatic heating within the whole volume of the model.

\section{Selected cases for experiment}

The selected cases for the experiment are Case A: 12 GMT 21 June 1975 (model initial time 12 GMT 20 June 1975) and

Case B: 12 GMT 25 June 1975 (model initial time 12 GMT 24 June 1975).

Case $A$ is a typical example of Baiu frontal heavy rainfalls not associated with a deep westerly trough. Case B is selected as a typical example of Baiu front associated with a deep westerly trough or cut-off vortex aloft.

\section{Outline of experiments}

In section 4, we will improve the convective adjustment scheme in several ways, and examine their performance in these selected cases to determine the most suitable scheme. In sections 5 and 6 , we analyse the structure of front predicted in the model with the improved convective adjustment scheme.

For the analysis, the predicted values on $\sigma^{-}$ surface are converted to the values on standard pressure levels. The analysis is made within the inner part of the prediction domain. The area for analysis covers the main part of the Japan Islands (Fig. 1B).

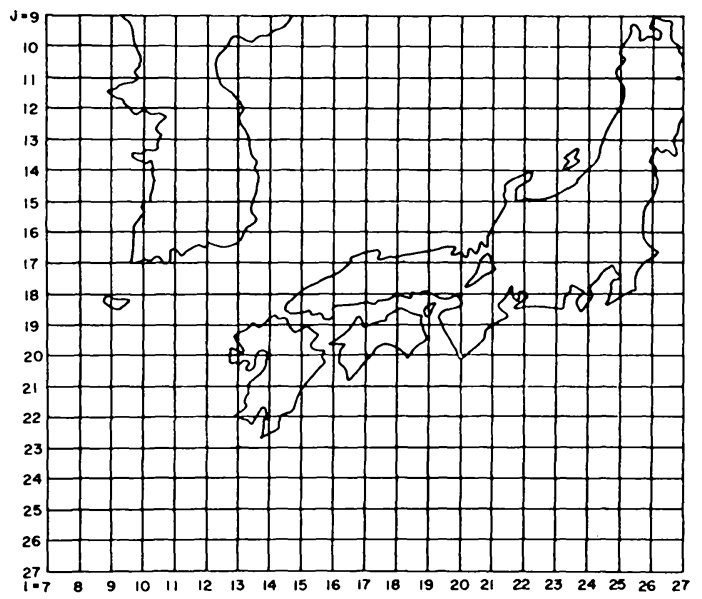

Fig. 1B Analysis area. 

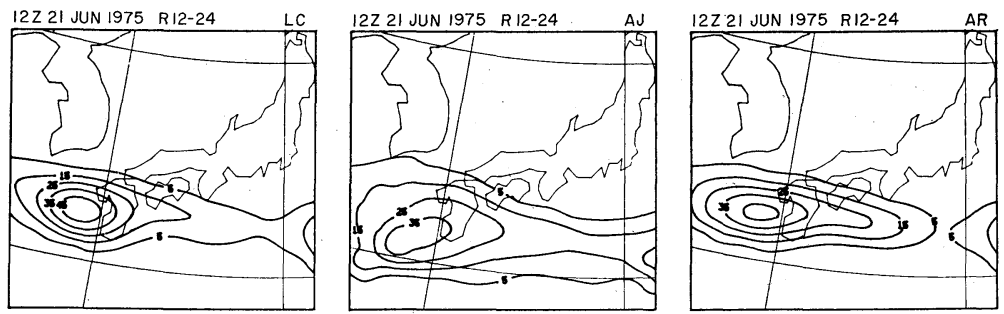

Fig. 2 LC, AJ and AR model predictions of 12-hour (12 24 hour) accumulated precipitation for 12 GMT 21 June 1975.

4. Convective adjustment scheme for $77 \mathrm{~km}$ mesh model

Test of convective adjustment scheme used in coarse-mesh model for $77 \mathrm{~km}$-mesh model

We explain first the "large-scale condensation" (i.e., condensation and released latent heat caused by grid-scale motions) and convective adjustment scheme used in 4L NHM-2 ( 380 km-mesh) and 6L FLM ( $150 \mathrm{~km}$-mesh).

Large-scale condensation: In the model the excess moisture is condensed and the latent heat is released when the air is over-saturated.

Convective adjustment: The dry and moist convective adjustment scheme proposed by Gadd and Keers (1970) is used to estimate condensation, released latent heat and convective transport of heat and moisture. In the moist convective adjustment scheme, the critical lapse rate $\gamma_{c}$ is defined as

$$
\gamma_{c}=\gamma_{d} \frac{1.0-\boldsymbol{B}_{m}}{1.0-\boldsymbol{B}_{c}}+\gamma_{m} \frac{\boldsymbol{B}_{m}-\boldsymbol{B}_{c}}{1.0-\boldsymbol{B}_{c}}
$$

where $\gamma_{d}, \gamma_{m}$ and $B_{m}$ are dry adiabatic lapse rate, moist adiabatic lapse rate and relative humidity in the layer under consideration. If $B_{m}$ exceedes critical value $B_{c}(0.5$ in these models) and the lapse rate exceedes $\gamma_{c}$, the scheme works to release the instability by adjusting stratification to $\gamma_{c}$ (see the detailed explanation in Gadd and Keers (1970)).

The $77 \mathrm{~km}$-mesh model including only "largescale condensation" is named as LC model, and the model including both "large-scale condensation" and the aforementioned adjustment scheme as AJ model hereafter in the present paper. We now examine the performances of LC and AJ model for 21 June 1975 case. The LC and AJ model predictions of 12-hour (12 24 hour) accumulated precipitation for 12 GMT 21 June 1975 are presented in Fig. 2. (See Fig. 6B for observed precipitation.) In LC model, rainfalls concentrated in a narrow zone though the amount is significantly small as compared with the observed. On the one hand in AJ model, the area of predicted heavy rain erroneously spreads to the south of the Japan Islands. It is also known that the surface pressure field is erroneously disturbed in the heavy rainfall area in $\mathrm{AJ}$ model (figure of the surface pressure is not presented).

This test indicates that the adjustment scheme designed for large meshs* is not always adequate for simulating Baiu frontal heavy rainfalls in small meshs. AJ model seems to be too sensitive to convectively unstable stratification of the tropical marine air mass. The fault of the adjustment scheme has been seen, for some extent, even in $150 \mathrm{~km}$ mesh 6L FLM. Nitta et al. (1979) pointed out that the adjustment scheme in that model tends to predict concentrated precipitation to the south of the surface disturbance compared to the observed, though they did not give any reasoning. In 6L FLM, the vertical motions are also disturbed and spotty patterns of vertical motion appears when the rainfalls are erroneously enhanced to the south of the disturbance.

\section{Improvement of adjustment scheme}

We will explore the reason why the adjustment scheme does not work adequately in the $77 \mathrm{~km}$-mesh model for Baiu frontal heavy rainfalls and seek the way of the simple improvement.

(1) Control through low-level vorticity

The adjustment scheme defined in eq. (1) is not directly controlled by the grid-scale circu-

* The precipitation predicted by the $380 \mathrm{~km}$-mesh LC model is very small as compared with that by the $380 \mathrm{~km}$-mesh AJ model (Ninomiya 1980). The fault of the adjustment scheme in the $380 \mathrm{~km}$ mesh model is not serious since the displacement of rainfall zone of $\sim 300 \mathrm{~km}$ to the south of Baiu front is beside the matter in hand for the model of $380 \mathrm{~km}$-mesh. 
lation but by the vertical instability at each grid point only. Obscrvations (Ninomiya and Yamazaki (1979), Akiyama (1979)) indicate, however, that thermal instability is released selectively in the vicinity of disturbances or within the frontal zone. Taking account of this, we try to control the adjustment through the low-level vorticity as

$$
\left.\begin{array}{l}
\text { apply adjustment } \cdots \cdots \cdots \text { for } \zeta \geq a \\
\text { not apply adjustment } \cdots \text { for } \zeta<a
\end{array}\right\}
$$

where $\zeta$ is the vorticity at $\sim 925 \mathrm{mb}$ and $a$ is a constant (e.g., $a=10 \times 10^{-5} \mathrm{sec}^{-1}$ ). The meteorological implication is that the upward motion due to the low-level frictional convergence is necessary to rise the air parcel up to the level of frec convection. Although this treatment is like somewhat the parameterization proposed by Ooyama (1964), the redistribution of heat and moisture in the present scheme is not decided by empirical function.

(2) Modification of the critical lapse ratc

Observational studies (Ninomiya (1978), Ninomiya and Yamazaki (1979), Akiyama (1979)) indicate that the unstable layer in which the lapse rate exceeds $\gamma_{c}$ or even $\gamma_{m}$ is frequently found in the vicinity of Baiu front. From this reason, the critical lapse rate $\gamma_{c}$ defined in eq (1) is presumably inadequate for simulating Baiu frontal rainfalls. We therefore modify (dilute) the critical lapse rate by a "blend" of $\gamma_{c}$ and $\gamma_{m}$ as

$$
\gamma_{c}^{*}=\alpha \gamma_{c}+(1-\alpha) \gamma_{d}
$$

where $\gamma_{c}{ }^{*}$ is the modified critical lapse rate, $\alpha$ is a constant (e.g., $\alpha=0.9$ or 0.8 ) and $\gamma_{c}$ is defined in eq. (1).

Because we have no theoretical basis to determine $a$ and $\alpha$, we should make predictions using various sets of $a$ and $\alpha$ to find the most adequate set of them. As for 21 June 1975 case, we find that values of $a=10 \times 10^{-6} \mathrm{sec}^{-1}$ and $\alpha=0.8$ are most adequate. The model with this improved adjustment scheme is called as AR model hereafter in this paper. The AR model prediction of 12-hour accumulated precipitation for this case is presented in Fig. 2.

Comparison between the predictions by LC and $A R$ model

There is no significant difference between $P_{\mathrm{sfc}}$ of these two models, though the figures are not presented. Along the Pacific coastal area of the southwestern part of Japan, rainfalls predicted in $\mathrm{AR}$ model are larger than that in LC model
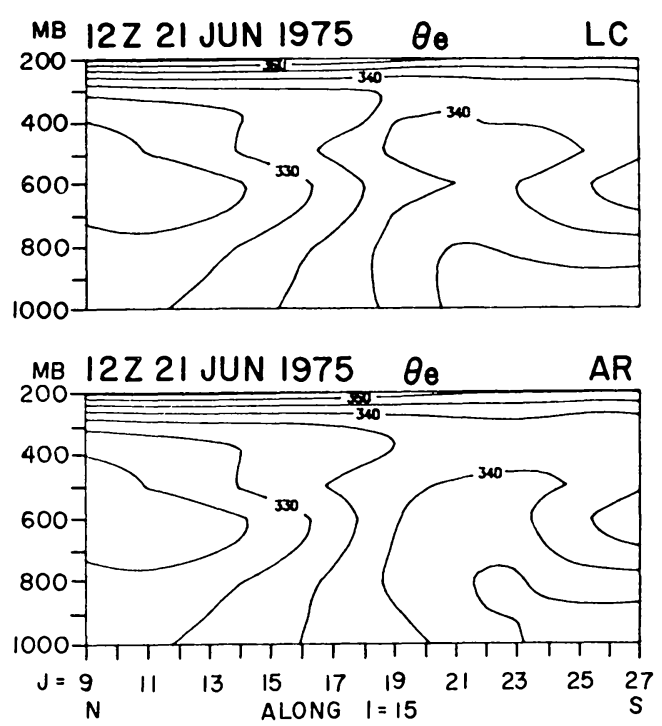

Fig. 3 Meridional vertical cross sections (along grid line $I=15$ ) of equivalent potential temperature $\theta_{e}$ predicted by $\mathrm{LC}$ and $\mathrm{AR}$ model for 12 GMT 21 June 1975.

by $\sim 10 \mathrm{~mm} / 12$ hour, though the maximum precipitation in AR model is approximately same to that in LC model.

The difference between the models is seen in the stratification. Fig. 3 are the meridional vertical sections (along grid line $I=15$, see Fig. 1B) of equivalent potential temperature $\theta_{e}$ predicted by LC and AR model. In AR model, approximately neutral stratification $\left(-\partial \theta_{e} / \partial p \approx 0\right)$ is formed within the frontal zone (over $J=19$ 21 on the abscisa in Fig. 3). In LC model, on the one hand, some thermal instability $\left(-\partial \theta_{e} /\right.$ $\partial p \approx-5 \mathrm{~K} / 200 \mathrm{mb}$ ) still remain within the frontal zone.

\section{Test for 25 June 1975 case}

12-hour accumulated rainfall for 12 GMT 25 June 1975 predicted by LC, AJ and AR model are presented in Fig. 4. In this case too, AJ model is inadequate since it produces heavy rainfalls to the south of the frontal zone. Among the predictions by the three modeis, prediction by AR model agrees best with the observed. The peak value of the rainfalls of AR model is larger than that of LC model by $\sim 10 \mathrm{~mm} / 12$ hour. Fig. 5 show the meridional vertical cross section of $\theta_{e}$ predicted by $\mathrm{LC}$ and $\mathrm{AR}$ model. The vertical gradient of $\theta_{e}\left(-\partial \theta_{e} / \partial p\right)$ within the frontal zone $(J=18 \sim 21)$ of AR model is $\sim 5 \mathrm{~K} /$ $600 \mathrm{mb}$ while that in LC model is $\sim 10 \mathrm{~K} / 600 \mathrm{mb}$, which indicates extremely strong instability. 
lation but by the vertical instability at each grid point only. Observations (Ninomiya and Yamazaki (1979), Akiyama (1979)) indicate, however, that thermal instability is released selectively in the vicinity of disturbances or within the frontal zone. Taking account of this, we try to control the adjustment through the low-level vorticity as

$$
\left.\begin{array}{l}
\text { apply adjustment } \cdots \cdots \cdots \text { for } \zeta \geq a \\
\text { not apply adjustment } \cdots \text { for } \zeta<a
\end{array}\right\}
$$

where $\zeta$ is the vorticity at $\sim 925 \mathrm{mb}$ and $a$ is a constant (e.g., $a=10 \times 10^{-5} \mathrm{sec}^{-1}$ ). The meteorological implication is that the upward motion due to the low-level frictional convergence is necessary to rise the air parcel up to the level of frec convection. Although this treatment is like somewhat the parameterization proposed by Ooyama (1964), the redistribution of heat and moisture in the present scheme is not decided by empirical function.

(2) Modification of the critical lapse rate

Observational studies (Ninomiya (1978), Ninomiya and Yamazaki (1979), Akiyama (1979)) indicate that the unstable layer in which the lapse rate exceeds $\gamma_{c}$ or even $\gamma_{m}$ is frequently found in the vicinity of Baiu front. From this reason, the critical lapse rate $\gamma_{c}$ defined in eq. (1) is presumably inadequate for simulating Baiu frontal rainfalls. We therefore modify (dilute) the critical lapse rate by a "blend" of $\gamma_{c}$ and $\gamma_{m}$ as

$$
\gamma_{c}^{*}=\alpha \gamma_{c}+(1-\alpha) \gamma_{d}
$$

where $\gamma_{c}{ }^{*}$ is the modified critical lapse rate, $\alpha$ is a constant (e.g., $\alpha=0.9$ or 0.8 ) and $\gamma_{c}$ is defined in eq. (1).

Because we have no theoretical basis to determine $a$ and $\alpha$, we should make predictions using various sets of $a$ and $\alpha$ to find the most adequate set of them. As for 21 June 1975 case, we find that values of $a=10 \times 10^{-6} \mathrm{sec}^{-1}$ and $\alpha=0.8$ are most adequate. The model with this improved adjustment scheme is called as AR model hereafter in this paper. The AR model prediction of 12-hour accumulated precipitation for this case is presented in Fig. 2.

Comparison between the predictions by $L C$ and AR model

There is no significant difference between $P_{\text {sfc }}$ of these two models, though the figures are not presented. Along the Pacific coastal area of the southwestern part of Japan, rainfalls predicted in $\mathrm{AR}$ model are larger than that in LC model
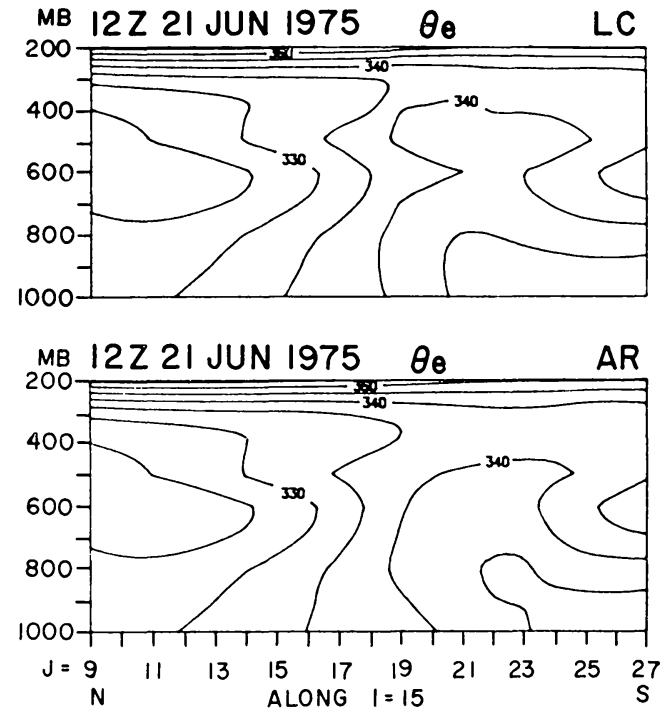

Fig. 3 Meridional vertical cross sections (along grid line $I=15$ ) of equivalent potential temperature $\theta_{e}$ predicted by $\mathrm{LC}$ and $\mathrm{AR}$ model for 12 GMT 21 June 1975.

by $\sim 10 \mathrm{~mm} / 12$ hour, though the maximum precipitation in AR model is approximately same to that in LC model.

The difference between the models is seen in the stratification. Fig. 3 are the meridional vertical sections (along grid line $I=15$, see Fig. 1B) of equivalent potential temperature $\theta_{e}$ predicted by LC and AR model. In AR model, approximately neutral stratification $\left(-\partial \theta_{e} / \partial p \approx 0\right)$ is formed within the frontal zone (over $J=19 \sim$ 21 on the abscisa in Fig. 3). In LC model, on the one hand, some thermal instability $\left(-\partial \theta_{e} l\right.$ $\partial p \approx-5 \mathrm{~K} / 200 \mathrm{mb}$ ) still remain within the frontal zone.

\section{Test for 25 June 1975 case}

12-hour accumulated rainfall for 12 GMT 25 June 1975 predicted by LC, AJ and AR model are presented in Fig. 4. In this case too, AJ model is inadequate since it produces heavy rainfalls to the south of the frontal zone. Among the predictions by the three modeis, prediction by AR model agrees best with the observed. The peak value of the rainfalls of AR model is larger than that of LC model by $\sim 10 \mathrm{~mm} / 12$ hour. Fig. 5 show the meridional vertical cross section of $\theta_{e}$ predicted by $\mathrm{LC}$ and $\mathrm{AR}$ model. The vertical gradient of $\theta_{e}\left(-\partial \theta_{e} / \partial p\right)$ within the frontal zone $(J=18 \sim 21)$ of AR model is $\sim 5 \mathrm{~K} /$ $600 \mathrm{mb}$ while that in LC model is $\sim 10 \mathrm{~K} / 600 \mathrm{mb}$, which indicates extremely strong instability. 

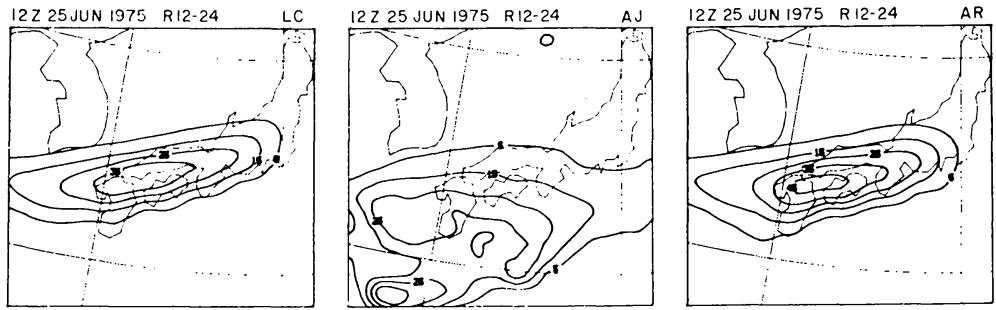

Fig. 4 LC, AJ and AR model predictions of 12-hour (12 24 hour) accumulated precipitation for 12 GMT 25 June 1975.
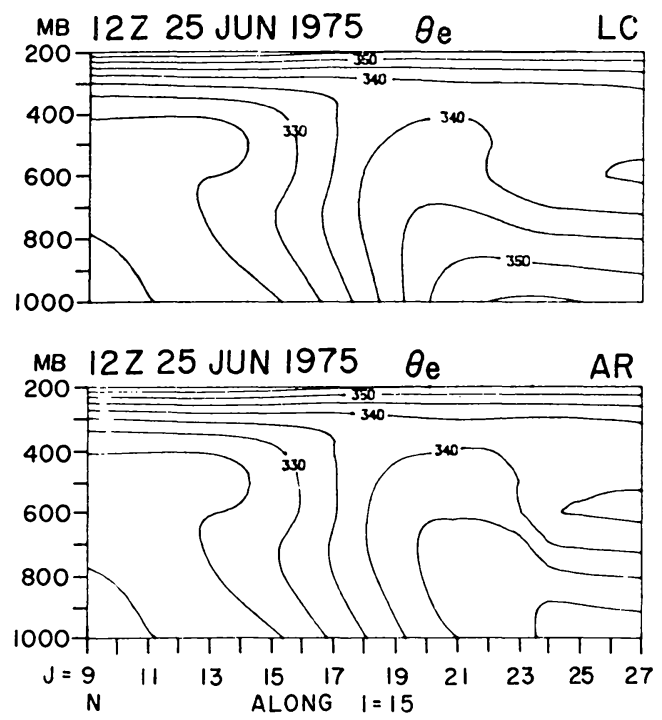

Fig. 5 Meridional vertical cross sections of $\theta_{e}$ predicted by LC and AR model for 12 GMT 25 June 1975.

\section{Summary of the present section}

It is shown from the tests for two typical cases of Baiu front that AR model including the improved convective adjustment scheme simulates most properly the heavy rainfalls concentrated within Baiu front and the approximately moist neutral stratification over the heavy rainfall zone.

It will be asked whether some disturbances may develop erroneously over Baiu front where the air is saturated and slightly unstable (i.e., $\gamma=\alpha \gamma_{m}+(1-\alpha) \gamma_{d}$ see eq. (3)). We ascertained that such erroneous development is not seen in 24-hour predictions by AR model for several cases of Baiu front.

Kondo (personal communication) can simulate the development of a squall line in the Midwest of U.S.A. in $40 \mathrm{~km}$-mesh primitive equation model which does not include any cumulus parameterization scheme. It may be infered from Kondo's result that the role of the cumulus parameterization scheme in a meso-mesh model may be less important as compared with that in a coarse-mesh model, since the magnitude of grid-scale upward motion become larger as the mesh size becomes smaller. The present test, however, shows that some cumulus parameterization is still necessary in this $77 \mathrm{~km}$-mesh model for predicting properly the stratification in Baiu front.

In the following sections, we will examine the features of Baiu front predicted by AR model and compare them with the observed features in detail.

\section{21 June 1975 (Case A) case study}

\section{Observed features}

The 850 and $500 \mathrm{mb}$ maps (manual analysis) at 12 GMT 21 June 1975 are shown in Fig. $6 \mathrm{~A}$, where the area enclosed by the thick line is the prediction area of the present experiment. A rainfall zone (Baiu front) and a weak trough at $850 \mathrm{mb}$ extend eastward from China to Japan along $\sim 30 \mathrm{~N}$ latitude circle. At $850 \mathrm{mb}$, temperature is low in Baiu front and thermal gradient of $\sim 2 \mathrm{~K} / 500 \mathrm{~km}$ is found to the south of the rainfall zone. A weak depression is located over the western part of Japan (Kyushu).

Centers of closed contour (low center) in polar frontal zone on $500 \mathrm{mb}$ map are located in 50 $60 \mathrm{~N}$. The large-scale trough does not reach south beyond $\sim 33 \mathrm{~N}$, and almost zonal flow prevails over Baiu front. A moist zone in which dewpoint depression $T-T_{d}$ is less than $2 \mathrm{~K}$ (stippled area) extends over the front. A zone of high temperature $(>-5 C)$ is found over the front.

Maps of observed winds at 700 and $300 \mathrm{mb}$ and 12-hour accumulated precipitation at 12 GMT 21 June 1975 are presented in Fig. 6B. Heavy rainfalls occures around the southwestern part of Japan. Rainfalls concentrate especially over Kyushu, where maximum precipitation 
reaches to $\sim 90 \mathrm{~mm} / 12$ hour.

At $700 \mathrm{mb}$, wind is weak $(\sim 10 \mathrm{knot}=5 \mathrm{~m} / \mathrm{sec})$ over the analyzed domain, except the area around the heavy rainfall zone. A zone of strong winds $(\sim 40 \mathrm{knot}=20 \mathrm{~m} / \mathrm{sec})$ appears to the south of the heavy rainfall zone. A distinct cyclonic circulation is formed to the north of Kyushu.
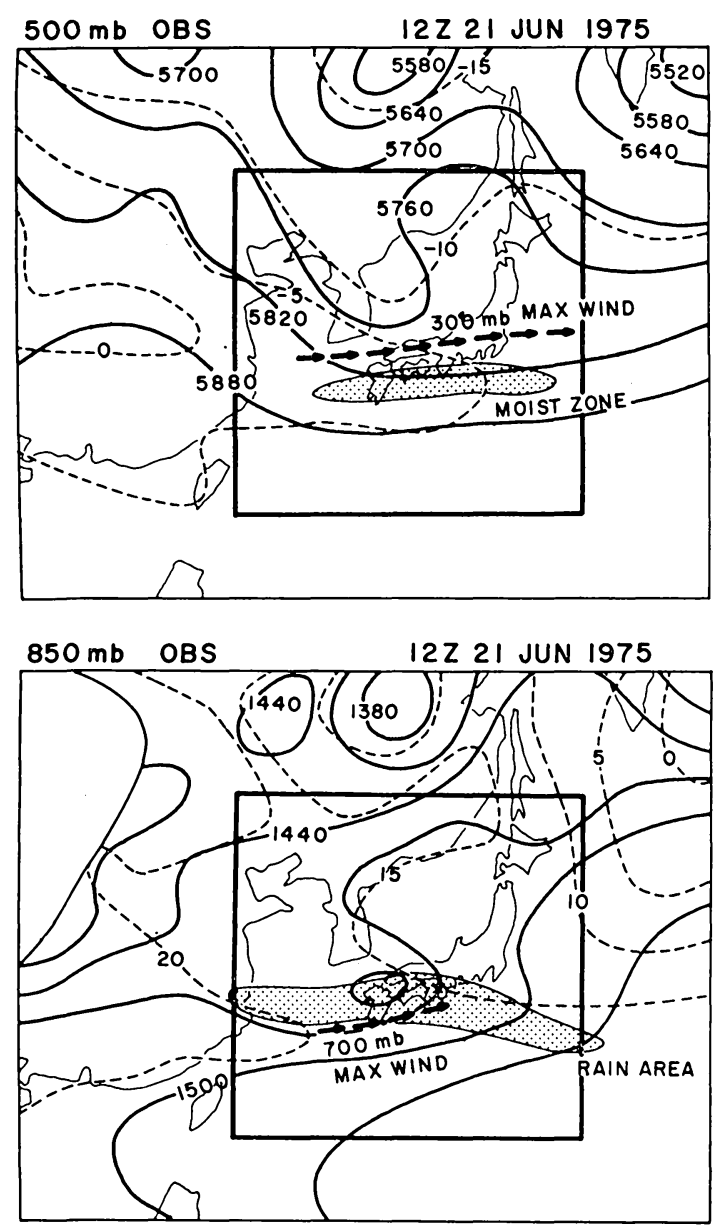

Fig. 6A 850 and $500 \mathrm{mb}$ maps (manual analysis) at 12 GMT 21 June 1975 . The area enclosed by the thick line is the area for prediction.
We find both cyclonic curvature of the flows and the strong cyclonic shear (i.e., wind shear in north-south dircction) over the heavy rainfall zone.

At $300 \mathrm{mb}$, the axis of upper jet stream $(\sim 35 \mathrm{~m} / \mathrm{sec})$ runs to the north of the heavy rainfall zone. Wind is weak $(\sim 15 \mathrm{~m} / \mathrm{sec})$ over and to the south of the heavy rainfall area. The flow at $300 \mathrm{mb}$ over and around the heavy rainfall area is therefore characterized by strong anticyclonic vorticity.

Pressure, height, wind and rainfall predicted by AR model

AR model predictions of the surface pressure $\left(P_{\mathrm{sfc}}\right), 900$ and $500 \mathrm{mb}$ height $\left(z_{900}\right.$ and $\left.z_{500}\right)$, 12-hour accumulated precipitation and wind speed at 700 and $300 \mathrm{mb}\left(\mathrm{V}_{700}\right.$ and $\left.\mathrm{V}_{300}\right)$ for 12 GMT 21 June 1975 are presented in Figs. 7 and 8 .

On the surface and $900 \mathrm{mb}$ maps a trough extends west to east from the East China Sea to the south of the Japan Islands. This trough corresponds, roughly speaking, to the frontal (or rainfall) zonc. The center of a frontal disturbance at $909 \mathrm{mb}$ is found over the western coast of Kyushu. Over the area to the south of $35 \mathrm{~N}$, the $500 \mathrm{mb}$ contours run almost parallel to latitude circles, though there is a weak westerly trough over the Korea Peninsular. In the present case, the middle tropospheric layer over the heavy rainfall zone is characterized by zonal flow and weak gradient of geopotential height $(\sim 60 \mathrm{~m} /$ $500 \mathrm{~km}$ ).

The predicted heavy rainfall zone extends from the East China Sea to the Pacific coast of Japan. The largest precipitation of $\sim 50 \mathrm{~mm} /$ 12 hour is predicted on the west coast of Kyushu.

At $300 \mathrm{mb}$, a zone of strong wind is formed along the north side of the heavy rainfall zone, though the predicted maximum wind speed $(\sim 27 \mathrm{~m} / \mathrm{sec})$ is smaller than the observed by $\sim 5 \mathrm{~m} / \mathrm{sec}$. At $700 \mathrm{mb}$, winds are weak $(\sim 5 \mathrm{~m} /$

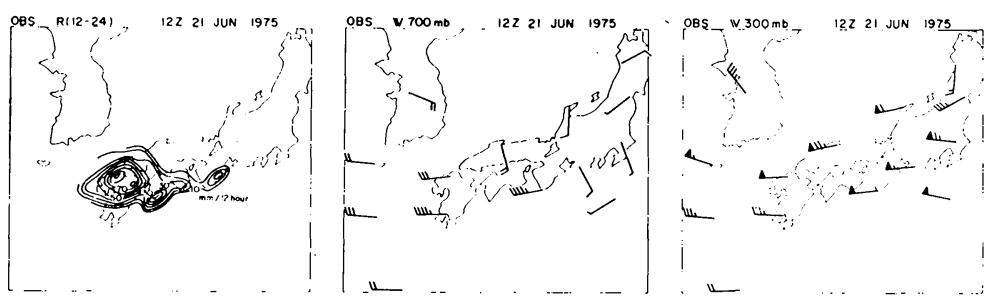

Fig. 6B The observed 12-hour accumulated precipitation, winds at 700 and $300 \mathrm{mb}$ at 12 GMT 21 June 1975. 

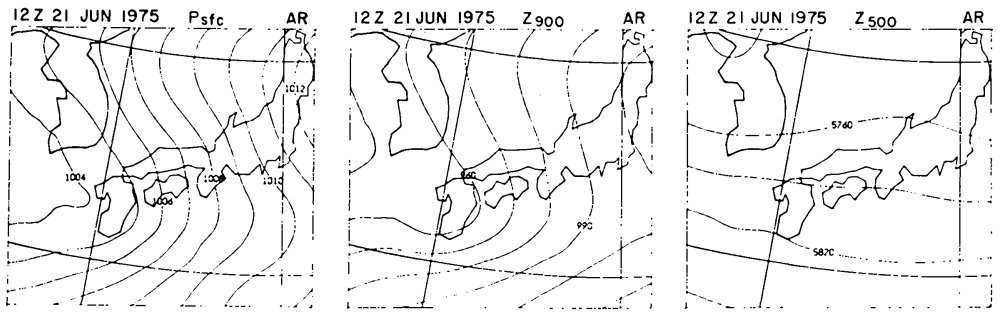

Fig. 7 AR model predictions of surface pressure $\left(p_{\mathrm{sfc}}\right), 900 \mathrm{mb}$ height $\left(z_{900}\right)$ and $500 \mathrm{mb}$ height $\left(z_{500}\right)$ for 12 GMT 21 June 1975.
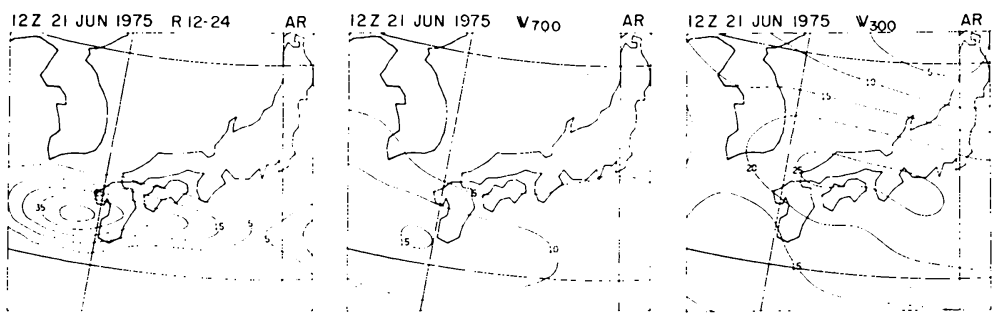

Fig. 8 AR model predictions of 12-hour accumulated precipitation, $700 \mathrm{mb}$ wind speed $\left(\boldsymbol{V}_{700}\right)$ and $300 \mathrm{mb}$ wind speed $\left(\boldsymbol{V}_{300}\right)$ for 12 GMT 21 June 1975.
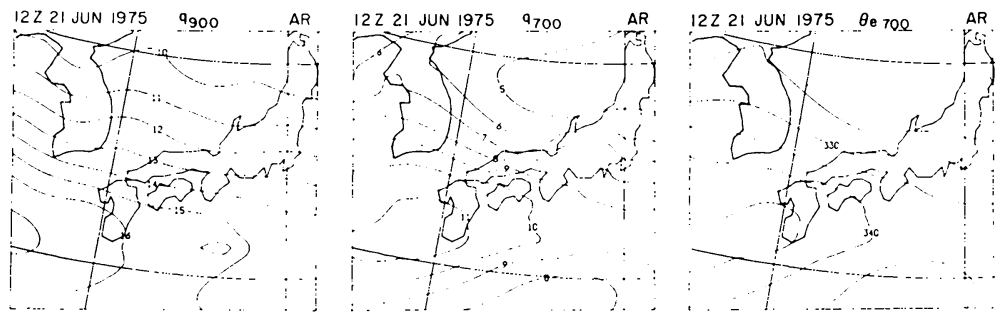

Fig. 9 AR model predictions of specific humidity at 900 and $700 \mathrm{mb}$ $\left(q_{900}\right.$ and $\left.q_{700}\right)$ and equivalent potential temperature at $700 \mathrm{mb}$ $\left(\theta_{e 700}\right)$ for 12 GMT 21 June 1975.

sec) to the north of $35 \mathrm{~N}$ and a zone of strong wind is formed along the south side of the heavy rainfall zone. The maximum wind speed in the "low-level strong wind core" is $\sim 15 \mathrm{~m} / \mathrm{sec}$, which is weaker than the observed by $\sim 5 \mathrm{~m} / \mathrm{sec}$.

It is ascertained for the present case, that the concentration of heavy rainfalls within the frontal zone and the spatial relation among the highlevel jet stream, heavy rainfall zone and the lowlevel strong wind core are predicted accurately to a certain extent by AR model, though the area of maximum rainfall is predicted $\sim 150 \mathrm{~km}$ southwest of the observed position and the maximum precipitation predicted is considerably small as compared with the observed.

\section{Moist tongue and frontal structure}

Maps of specific humidity at 900 and $700 \mathrm{mb}$ ( $q_{900}$ and $q_{700}$ ) and equivalent potential temperature at $700 \mathrm{mb}\left(\theta_{e 700}\right)$ predicted by AR model for 12 GMT 21 June 1975 are shown in Fig. 9. At $900 \mathrm{mb}$, the area of high specific humidity more than $\sim 15 \mathrm{~g} / \mathrm{kg}$, which corresponds to the area of the tropical marine air mass, spreads to the south and southwest of the Japan Islands. We find, at $700 \mathrm{mb}$, a moist tongue (elongated moist zone) along the heavy rainfall zone and two dry zones to the north (over the Japan Sea) and south (over the Pacific) of the moist tongue.

The map of $\theta_{e 700}$ shows a zone of high $\theta_{e}$ around the heavy rainfall zone. The zone of high $\theta_{e}$ in $700 \sim 300 \mathrm{mb}$ coinsides with the zone of "diabatic heating*" $\delta \theta / \delta t$ in AR model pre-

* The "diabatic heating" $\delta \theta / \delta t$ is defined as the grid-scale diabatic heating in the modcl. $\delta \theta / \delta t$ is the change of $\theta$ due to the release of latent heat and the vertical convergence of convective and eddy (in the process of diffusion and heat exchange between the sea and the air) heat transport in AR model. 
$12 Z 21$ JUN 1975

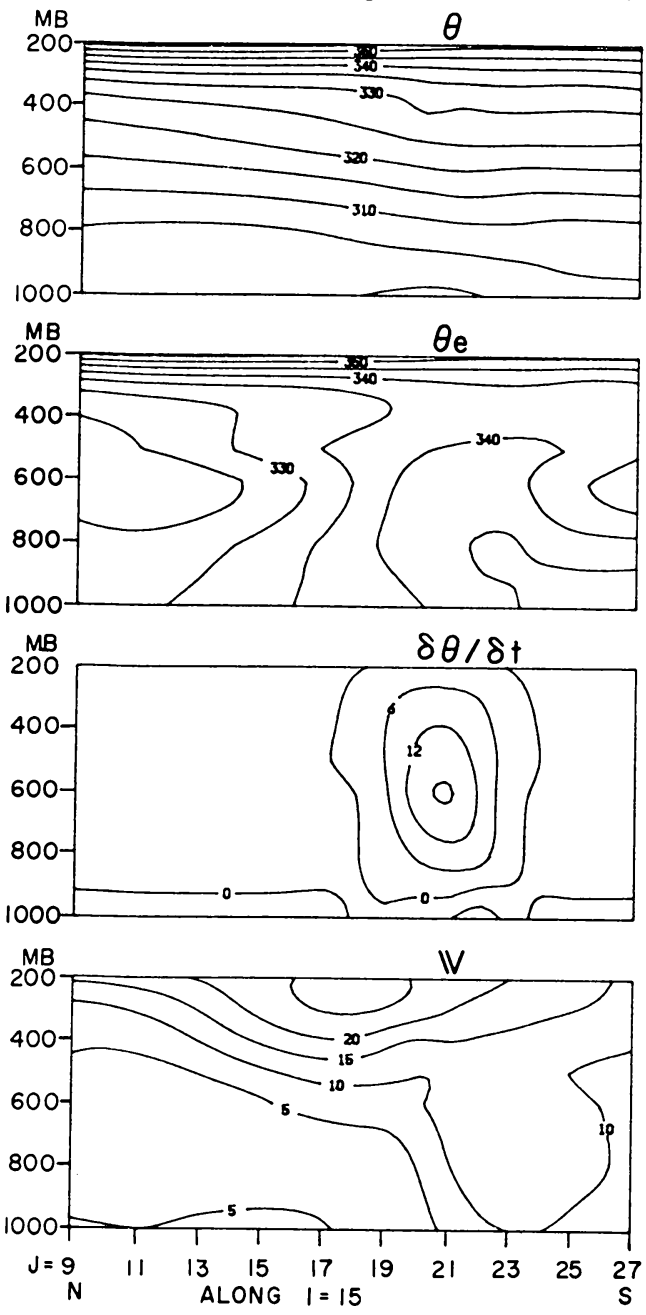

Fig. 10 Meridional vertical cross sections (along grid line $I=15$ ) of potential temperature $(\theta)$, equivalent potential temperature $\left(\theta_{e}\right)$ diabatic change of potential temperature $(\delta O / \delta t$ unit in $\mathrm{K} / 12$ hour) and wind speed $(\boldsymbol{V})$ predicted by AR model for 12 GMT 21 June 1975.

diction (see Fig. 12) and presumably attributed to the release of latent heat and the vertical convergence of convective heat and moisture transport.

The meridional vertical cross sections (along grid line $I=15)$ of $\theta, \theta_{e}$, "diabatic heating*" $\delta \theta / \delta t$ and wind speed predicted by AR model for 12 GMT 21 June 1975 are presented in Fig. 10. The heavy rainfall zone is located over grid points of $J=19 \sim 22$ in the abscissa of Fig. 10.

The meridional gradient of $\theta$ in the frontal zone is weak $(\sim 2 \mathrm{~K} / 500 \mathrm{~km})$ while the gradient of $\theta_{e}$ is strong $(\sim 10 \mathrm{~K} / 300 \mathrm{~km})$ in $900 \sim 700 \mathrm{mb}$ to the north of the heavy rainfall zone. The vertical instability is released in the frontal zone and consequently approximately neutral stratification is formed there while the strong convective instability remaines adequately in the tropical air mass to the south of the Japan Islands.

The third figure shows the "diabatic heating" $(\delta \theta / \delta t$ unit is in $\mathrm{K} / 12$ hour) concentrated in the frontal zone. The vertical profile (maximum at $\sim 600 \mathrm{mb}$ ) and the magnitude (maximum value $\sim 1.5 \mathrm{~K} /$ hour) of $\delta \theta / \delta t$ seem to be adequate as far as judging from the observational evaluations (e.g., Yoshizumi (1977b), Ninomiya (1971, 1974)). In the bottom figure (wind speed), there are a low-level $(\sim 700 \mathrm{mb})$ and a high-level $(\sim 200 \mathrm{mb})$ wind maxima to the south and the north of the heavy rainfall zone respectively.

Figs. 9 and 10 indicate that AR model can simulate the features of the moist tongue, convective w. ming and the structure of Baiu front quiet projurly as far as concerning the present case.

\section{Vertical structure of frontal disturbance}

AR model predictions of vorticity at 700 and $300 \mathrm{mb}\left(\zeta_{700}\right.$ and $\left.\zeta_{300}\right)$, vertical $p$-velocity at $700 \mathrm{mb}\left(\omega_{700}\right)$, wind vector relative to the frontal disturbance at 700 and $300 \mathrm{mb}\left(\boldsymbol{V}_{700}-\boldsymbol{C}\right.$ and $V_{300}-C$ ) and $\delta \theta / \delta t$ (unit is in $\mathrm{K} / 12$ hour) at $700 \mathrm{mb}$ for 12 GMT 21 June 1975 are shown in Figs. 11 and 12.

The cyclonic vorticity of the frontal disturbance is restricted within the lower troposphere $(1,000 \sim 600 \mathrm{mb})$, though the strong upward motion reaches up to $300 \mathrm{mb}$. The strong anticyclonic vorticity appears in $300 \sim 200 \mathrm{mb}$ over the low-level cyclonic vorticity. The vertical axis of the frontal disturbance inclines northward with height. (Cyclonic circulation center at $700 \mathrm{mb}$ is located at $\sim 32 \mathrm{~N}$ while that at $300 \mathrm{mb}$ is at $\sim 36 \mathrm{~N}$.) The predicted features resemble the observed features of the Baiu frontal disturbance.

Relative winds at $300 \mathrm{mb}$ also show the difluent flow with anticyclonic vorticity and divergence over the area of maximum diabatic heating (or maximum precipitation). These features are like the features of upper outflow over the intence convections (e.g., Fankhauser (1969), Ninomiya (1971, 1974b), Ninomiya and Akiyama (1973) and MacDonald (1977)).

It is concluded in this subsection that this frontal disturbance associated with heavy rain- 

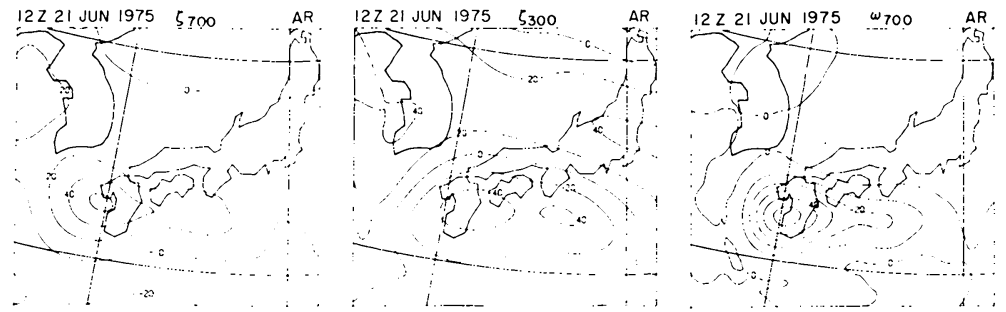

Fig. 11 AR model predictions of vorticity at 700 and $300 \mathrm{mb}\left(\zeta_{700}\right.$, $\zeta_{300}$ unit in $10^{\left.-6 \cdot \sec ^{-1}\right)}$ and vertical $p$-velocity $\left(\omega_{700}\right.$ unit in $\mathrm{mb} /$ hour) for 12 GMT 21 June 1975.
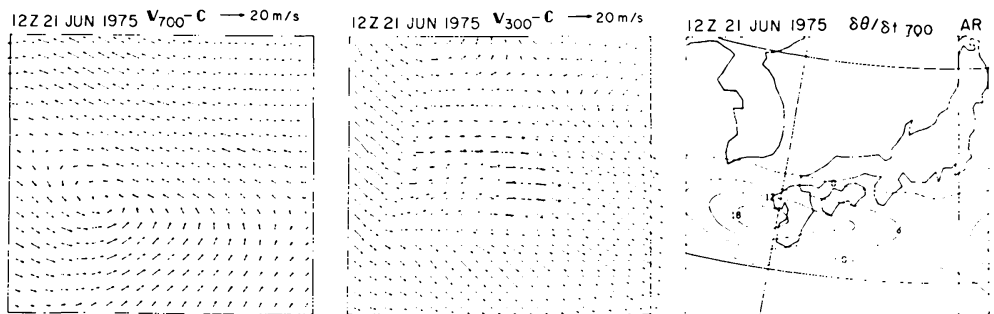

Fig. 12 AR model predictions of 700 and $300 \mathrm{mb}$ winds relative to the frontal depression $\left(\boldsymbol{V}_{700}-\boldsymbol{C}, \boldsymbol{V}_{300}-\boldsymbol{C}\right)$ and diabatic change of $\theta$ at $700 \mathrm{mb}\left(\delta \theta / \delta t_{700}\right.$ unit in $\mathrm{K} / 12$ hour) for $12 \mathrm{GMT}$ 21 June 1975.

falls is properly simulated by AR model.

\section{25 June 1975 (Case B) case study}

\section{Observed features}

Fig. 13A shows 850 and $500 \mathrm{mb}$ maps (manual analysis) for 12 GMT 25 June 1975. Maps of observed winds at 700 and $300 \mathrm{mb}$ and 12-hour accumulated precipitation at 12 GMT 25 June 1975 are presented in Fig. 13B.

A predominant cut-off vortex aloft and the surface depression is located over the Japan Sea and the Japan Islands $(\sim 35 \mathrm{~N}, \sim 135 \mathrm{E})$ respec- tively. Polar and subtropical jet streams tend to marge over the East China Sea forming an axis of strong winds over the Japan Islands. Rainfall zone (Baiu front) extends from China to the southern rim of the cut-off vortex. It is also seen that the front is located along the northern boundary of the tropical marine air mass. At $500 \mathrm{mb}$, the moist zone in which $T-T_{d}$ is less than 2C (stippled area) and the warm belt extend over the heavy rainfall zone.

Heavy rainfalls concentrate around the surface front and the maximum precipitation reaches to
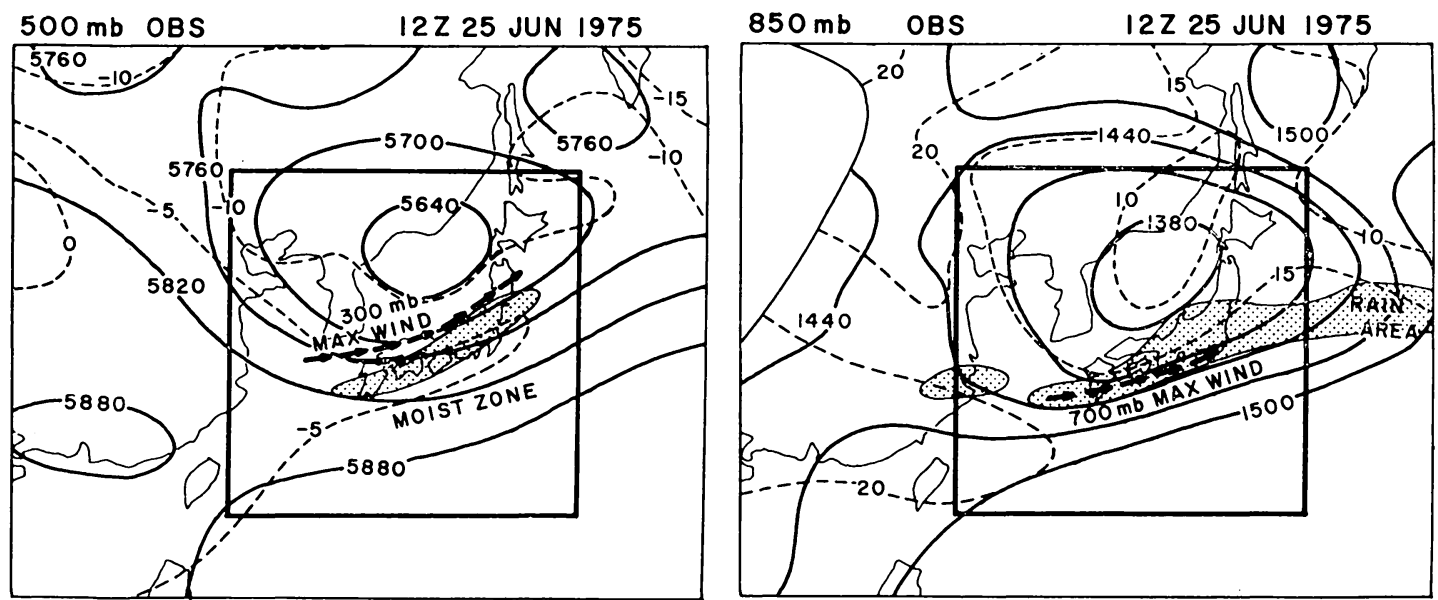

Fig. 13A 850 and $500 \mathrm{mb}$ maps (manual analysis) at 12 GMT 25 June 1975. 

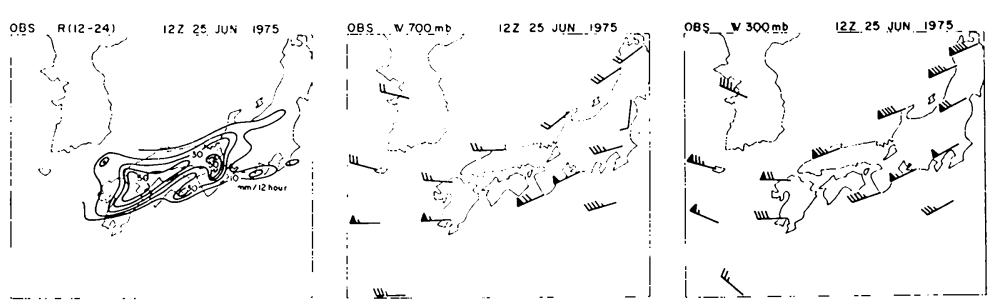

Fig. 13B The obscrved 12-hour accumulated precipitation, $\boldsymbol{V}_{700}$ and $V_{300}$ at 12 GMT 25 June 1975.
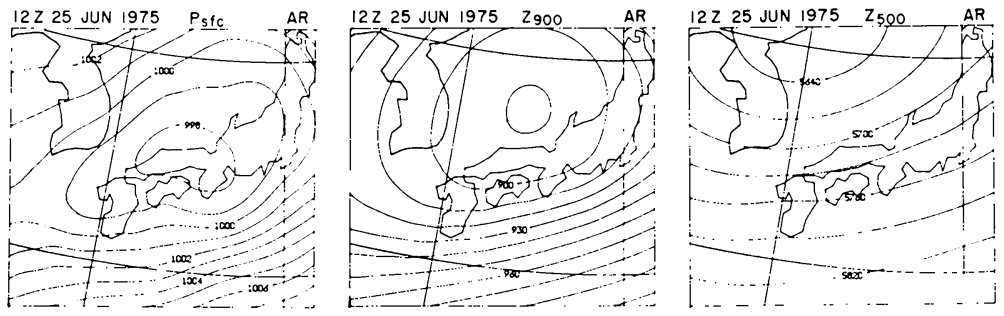

Fig. 14 AR model predictions of $p_{\mathrm{sfc}}, z_{900}$ and $z_{500}$ for 12 GMT 25 June 1975.
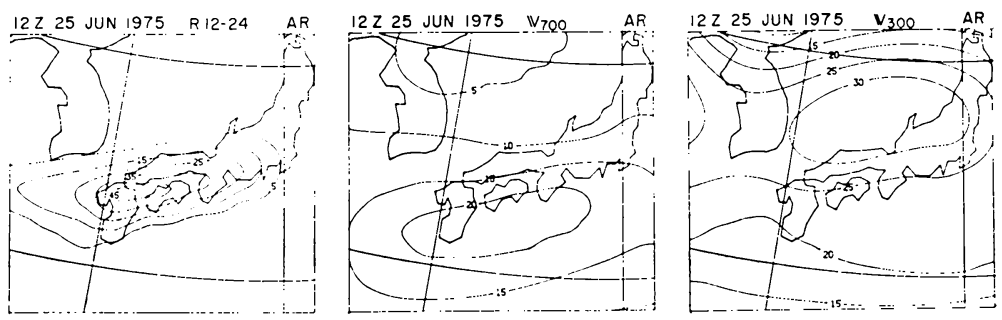

Fig. 15 AR model predictions of 12 -hour accumulated precipitation, $V_{700}$ and $\boldsymbol{V}_{300}$ for 12 GMT 25 June 1975.

$\sim 60 \mathrm{~mm} / 12$ hour. A zone of low-level $(\sim 700$ $\mathrm{mb})$ strong wind $(25 \sim 30 \mathrm{~m} / \mathrm{sec})$ over the Pacific coast is located to the south of the heavy rainfall zone and consequently a zone of strong cyclonic vorticity is found over the heavy rainfall zone. At higher levels $(300 \sim 200 \mathrm{mb})$, jet stream $(\sim 40 \mathrm{~m} / \mathrm{sec})$ over the Japan Sea coast is located to the north of the heavy rainfall zone, while the winds over the Pacific coast is significantly weak $(\sim 20 \mathrm{~m} / \mathrm{sec})$. At the higher levels, therefore, a zone of strong anticyclonic vorticity is formed over the heavy rainfall zone.

Pressure, height, wind and rainfall predicted by AR model

AR model predictions of $p_{\mathrm{sfc}}, z_{900}, z_{500}, 12-$ hour accumulated precipitation, $\boldsymbol{V}_{700}$ and $\boldsymbol{V}_{300}$ for 12 GMT 25 June 1975 are presented in Figs. 14 and 15. Comparing Figs. 13, 14 and 15, we find that the predicted position of the heavy rainfall zone along the surface trough (i.e., front) and the amount of rainfall (maximum $\sim 50 \mathrm{~mm}$ /
12 hour) agree well with the observed. Although the predicted maximum wind speed in the high and low-level strong wind zone are smaller than the observed by $5 \sim 10 \mathrm{~m} / \mathrm{sec}$, these locations relative to the heavy rainfall zone are accurately predicted.

\section{Moist tongue and frontal structure}

Maps of $q_{900}, q_{700}$ and $\theta_{e 700}$ predicted by AR model for 12 GMT 25 June 1975 are shown in Fig. 16. Figures in Fig. 17 are the meridional vertical cross sections (along grid line $I=15$ ) of $\theta, \theta_{e}, \delta \theta / \delta t$ (unit in $\mathrm{K} / 12$ hour) and wind speed predicted by AR model.

The area of high specific humidity $(\geq 15 \mathrm{~g} / \mathrm{kg})$ at $900 \mathrm{mb}$ corresponds to the area of the tropical marine air mass. In this case too, the zone of high specific humidity and high equivalent potential temperature elongating along the southern rim of the heavy rainfall zone are seen on $700 \mathrm{mb}$ map.

The frontal structure of the Cases B (Fig. 17) 

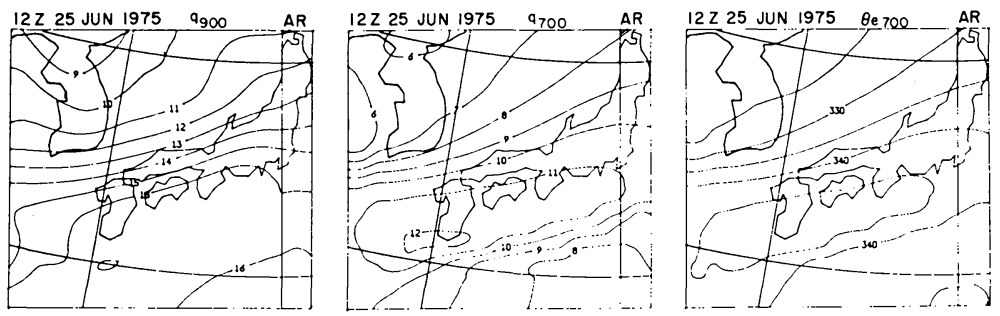

Fig. 16 AR model predictions of $q_{900}, q_{700}$ and $\theta e 700$ for 12 GMT 25 June 1975.

$12 Z 25$ JUN 1975

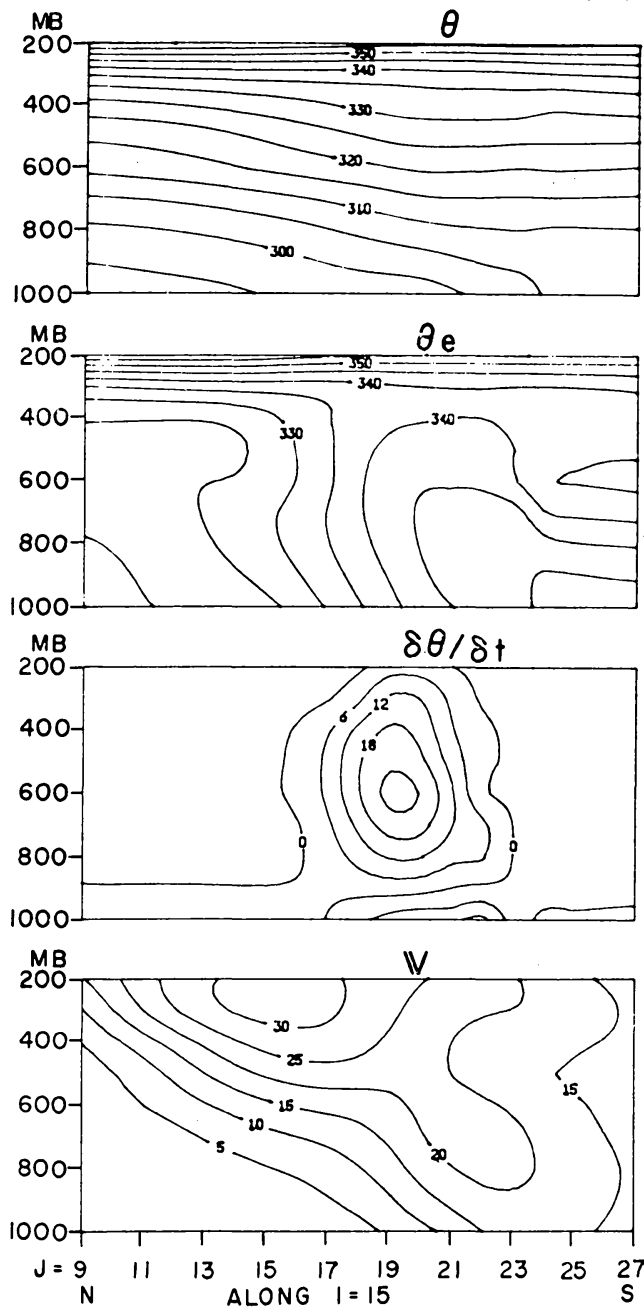

Fig. 17 Meridional vertical cross sections (along grid line $I=15)$ of $\theta, \theta_{\mathrm{e}}, \delta \theta / \delta t(\mathrm{~K} / 12$ hour) and $\mathrm{V}$ predicted by AR model for 12 GMT 25 June 1975.

is similar to that of Case A (Fig. 10). The meridional gradient of $\theta$ in the frontal zone is weak $(\sim 5 \mathrm{~K} / 500 \mathrm{~km})$ while that of $\theta_{e}$ is strong $(\sim 10 \mathrm{~K} / 300 \mathrm{~km})$. The release of vertical instability and the formation of the moist neutral stratification are confined within the frontal zone, while the strong convective instability remains in the tropical marine air mass to the south of the frontal zone.

The maximum of $\delta \theta / \delta t(\sim 2 \mathrm{~K} /$ hour $)$ appears at $600 \mathrm{mb}$ over the heavy rainfall zone. In the bottom figure in Fig. 17, the low-level $(\sim 700 \mathrm{mb})$ and high-level $(\sim 200 \mathrm{mb})$ wind maxima are situated to the north and the south of the maximum diabatic heating $(\delta \theta / \delta t)$ respectively.

\section{Vertical structure of frontal disturbance}

AR model predictions of $\zeta_{700}, \zeta_{300}, \omega_{700}$, $V_{900}-C, V_{300}-C$ and $\delta \theta / \delta t_{700}$ (unit in $\mathrm{K} / 12$ hour) for 12 GMT 25 June 1975 are presented in Fig. 18 and 19.

The cyclonic vorticity in the frontal zone is restricted within the lower layer $(1,000 \sim 700 \mathrm{mb})$ and the strong anticyclonic vorticity appears in the upper layer $(300 \sim 200 \mathrm{mb})$ over the heavy rainfall zone. The center of cyclonic circulation of the depression at $900 \mathrm{mb}$ is situated at $\sim 33 \mathrm{~N}$ and $\sim 130 \mathrm{E}$. The vertical axis of the depression inclines northward with height. Relative wind vectors at $300 \mathrm{mb}$ show the difluent flow with anticyclonic vorticity and divergence over the area of strong diabatic heating.

It is concluded, in this case too, the predicted Baiu front with heavy rainfalls exhibits the characteristics of Baiu front found in the observational studies.

\section{Concluding remarks}

In the present study we make real data forecast experiments of heavy rainfall in Baiu front (a stational front in the Asian subtropical humid region) using a 6-level $77 \mathrm{~km}$-mesh primitive equation model.

We examine first whether the moist convective adjustment scheme which has been used in coarse-mesh models is suitable for the present 

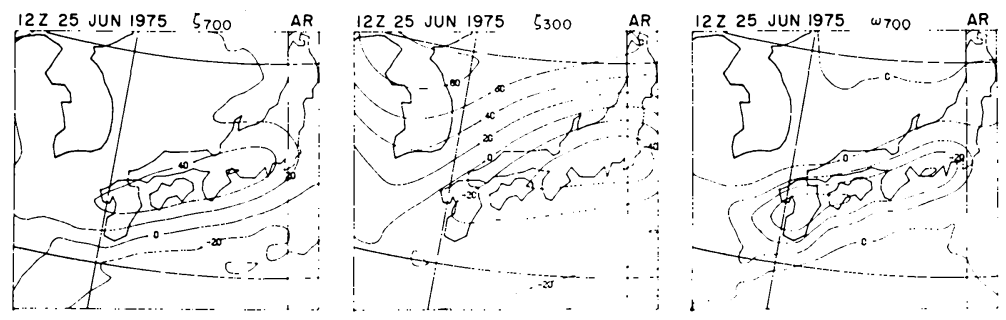

Fig. 18 AR model predictions of $\zeta_{700}, \zeta_{300}$ and $\omega_{700}$ for 12 GMT 25 June 1975.
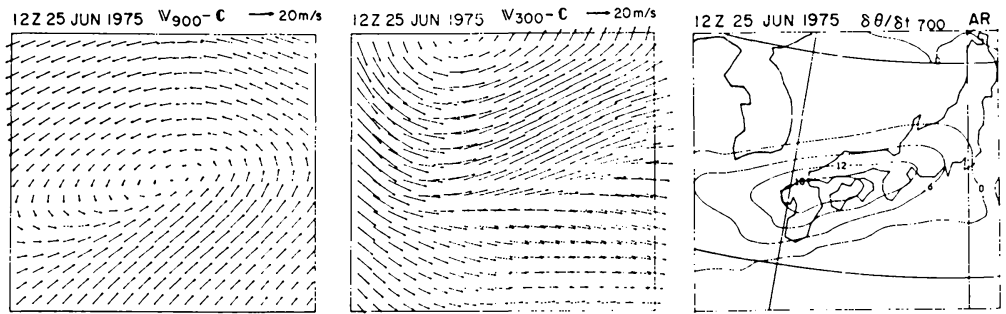

Fig. 19 AR model predictions of $\mathrm{V}_{700}-\mathrm{C}, \mathrm{V}_{300}-\mathrm{C}$ and $\delta \theta^{/} \delta t_{700}$ (K/12 hour) for 12 GMT 25 June 1975.

model or not. Experiments show that the scheme is not suitable because it tends to produce heavy rainfalls to the far south of the front. In order to confine heavy rainfalls within the front or in the vicinity of frontal depression, we improve the scheme by controlling the adjustment through the low-level vorticity and by modifying the critical lapse rate used in the scheme.

We make real data forecast experiment by the model including the improved adjustment scheme for two typical cases of Baiu frontal heavy rainfalls (21 June 1975 and 25 June 1975 cases). In both cases, the predicted rainfalls concentrate within the frontal zone. The heavy rainfall zone appears to the south of subtropical jet stream. The core of the low-level $(\sim 700 \mathrm{mb})$ strong wind is formed to the south of the heavy rainfall zone. The moist tongue (at $\sim 700 \mathrm{mb}$ ) and a zone of convective warming $(700 \sim 400 \mathrm{mb})$ are predicted along the front. The wind field of the frontal depression associated by the heavy rainfall is characterized by the low-level cyclonic vorticity with convergence and the upper-level anticyclonic vorticity with divergence and difluence. The level of maximum adiabatic heat ing $(\delta \theta / \delta t=1 \sim 2 \mathrm{~K} /$ hour $)$ is found around $600 \mathrm{mb}$.

It is encouraging to find that features of the predicted front and frontal depressions agree with the features observed. Results of the experiments will indicate the possibility in improve- ment of quantitative prediction of Baiu frontal heavy rainfall within the framework of conventional premitive equation model.

We should note that the experiments of the present study do not include the case of a typical medium-scale disturbance. It is a remaining problem to ascertain whether the present model can simulate accurately the medium-scale disturbance (wave length $\sim 1,000 \mathrm{~km}$ ) or not. It is also necessary to examine in more detail the behavior of the heavy convective rainfalls in the Asian subtropical humid region in the present model for various cases to ascertain the ability of the present model. It is also expected that the improvement in prediction accuracy of rainfall will be achieved through the inclusion of the precise topography and the physical processes in the boundary layer. These remaining problems will be discussed and explored in the future works.

\section{Acknowledgements}

The authors would like to express their hearty thanks to Mr. Y. Takigawa of Electronic Computation Center, JMA for providing the prediction values of $4 \mathrm{~L}-\mathrm{NHM} 2$ which are used for the boundary values of the present model.

\section{References}

Akiyama, T., 1973a: The large-scale aspects of the characteristic features of the Baiu front. Pap. 
Met. Geophy., 24, 157-188.

1973b: Frequent occurrence of heavy rainfall along the north side to the low-level jet stream in the Baiu season. Pap. Met. Geophy., 24, 379-388.

- 1975: Southerly transversal moisture flux into the extremely heavy rainfall zone in the Baiu season. J. Met. Soc. Japan, 53, 304-316. _ 1978: Mesoscale pulsation of convective rain in medium-scale disturbances developed in Baiu front. J. Met. Soc. Japan, 56, 267-273.

1979: Thermal stratification in Baiu frontal medium-scale disturbances with heavy rainfalls. J. Met. Soc. Japan, 57, 587-598.

Anthes, R. A., and D. Keyser, 1979: Tests of a finemesh model over Europe and the United States. M. W. Rev., 107, 963-984.

Davis, H.C., 1976: A lateral boundary formulation for multi-level prediction models. Quart. J. Roy. Met. Soc., 102, 405-418.

Fankhauser, J.C., 1969: Convective processes resolved by a mesoscalc rawinsonde network. $J$. App. Met., 8, 778-798.

Gadd, A. J. and J. F. Keers, 1970: Surface exchanges of sensible and latent heat in a 10-level model atmosphere. Quart. J. Roy. Met. Soc., 96, 297-308.

Hovermale, J., 1975: Accuracy of prediction of heavy precipitation events in relation to grid resolution in numerical models. Briefing of performance of NMC hurricane modelat NOAA/ NMC Hurricane Confer. at Miami 1975.

Keyser, D., M. A. Shapiro and D. J. Perkey, 1978: An examination of frontal structure in a finemesh primitive equation model for numerical weather prediction. M.W. Rev., 106, 1112-1124.

Kikuchi, Y., et al., 1977: Four-level northern hemispheric primitive equation model. Periodic Report on Numerical Weather Prediction XVII by JMA. 27-39.

Leith, C. E., 1969: Two dimentional eddy viscosity coefficients. Proc. WMO/IUGG Symp. Num. Wea. Pred., Tokyo 1968, JMA., 1-41.

MacDonald, A.E., 1977: On a type of strong divergent steady state. $M . W$. Rev., 105, 771785 .

Matsumoto, S., et al., 1970: On the structure of the Baiu front and the associated intermediate-scale disturbances in the lower atmosphere. J. Met. Soc. Japan, 48, 479-491.

- , et al., 1971: Characteristic features of Baiu front associated with heavy rainfall. J. Met. Soc. Japan, 49, 267-281.

and medium-scale structure of a cold front and the relevant vertical circulation. J. Met. Soc. Japan, 49, 648-662.

Miyakoda, K. ard A. Rosati, 1977: One-way nested grid models: The interface conditions and the numerical accuracy. M.W. Rev., 105, 10921107.

Ninomiya, K., 1971: Dynamical analysis of outflow from tornado-producing thunderstorms as revealed by ATS-III pictures. J. App. Met., 10, 275-294.

_ _ 1974a: Bulk properties of cumulus convections in the small area over Kuroshio region in February 1968. J. Met. Soc. Japan, 52, 188 203.

1974b: Mesoscale objective analysis of the wind and moisture field around the thunderstorms developed over NSSL observation network on May 28, 1967. Pap. Met. Geophy., 25, 8197.

, 1978: Heavy rainfalls associated with frontal depression in Asian subtropical humid region (I). J. Met. Soc. Japan, 56, 253-266.

1980: Enhancement of Asian subtropical front from thermodynamic effect of cumulus convections. J. Met. Soc. Japan, 58, 1-15.

of the medium-scale disturbance in the Baiu front. J. Met. Soc. Japan, 49, 663-677.

— clusters in the Baiu front as revealed by multiradar composite echo maps (II). J. Met. Soc. Japan, 51, 108-118.

, and 1974: Band structure of mesoscale echo cluster associated with low-level jet stream. J. Met. Soc. Japan, 52, 300-313. and $\mathrm{K}$. Yamazaki, 1979: Heavy rainfalls associated with frontal depression in Asian subtropical humid region (II). J. Met. Soc. Japan, 57, ?

Nitta, Ta., Y. Yamagishi and Y. Okamura, 1979: Operational performance of a regional numerical weather prediction model. J. Met. Soc. Japan, 57, 399-413.

Ooyama, K., 1964: A dynamical model for the study of tropical cyclone development. Geofis. Intern., 4, 187-198.

Parkey, D. J., 1976: A description and preliminary results from a fine-mesh model for forecasting quantitative precipitation. M.W. Rev., 104, 1513-1526.

Tokioka, T., 1973: A stability study of mediumscale disturbances with inclusion of convective effects. J. Met. Soc. Japan, 51, 1-10.

Yoshizumi, S., 1977a: On the structure of intermediate-scale disturbances on the Baiu front. $J$. Met. Soc. Japan, 55, 107-120.

1977b: Preliminary report on the convective vertical transport of momentum over western Japan in the Baiu season. Pap. Met. Geophy., 28, 49-61. 


\title{
6 層 $77 \mathrm{~km}$ 格子プリミテブモデルにおける梅雨前線と大雨
}

\author{
二宮 洸 三*・哄保夫 \\ 気像们電計室
}

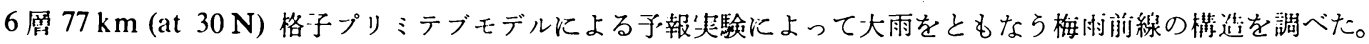

まずコアス・メッシュ( $380 \mathrm{~km}, 150 \mathrm{~km})$ モデルに使用されてきた湿潤対流調節方式がこのモデルで適当かどう かを調べたが，それが前線の 2 300 km 南に大きな降水をもたらす倾问をもつことがわかった。この久点を收良す るため対流調節を下層の渦度でコントロールし，クリテカルラブスレートをゆるめることにした。

この改良された湿润対流調節を含むモデルで典型的な梅雨前線 2 例（1975年 6 月21山および25日）の\}報失験を行

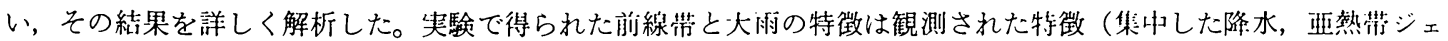

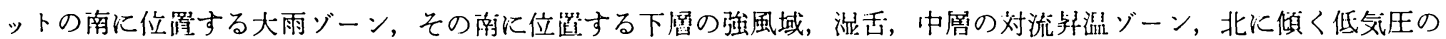
垂直構造，非断熱熱源の垂直分布など）によく一致しており，梅雨前線と大雨がかなり正確にシュミレートされたこ とがわかった。

* 気象研究所併任 